\title{
القيم الأخلاقية في سورة الإسراء وتنميتها للأطفال والبالغين
}

\author{
Nur Laily Fauziyah \\ STIT Al Marhalah Al Ulya Bekasi \\ Email: lailyfauziyah@gmail.com
}

\begin{abstract}
The good character decorates human. It makes him loved in society and is one of the reasons for the happiness of man in this life and to enter Paradise in the Hereafter. Bad manners cause human agony and entering the fire in the Hereafter. As we have seen in the time of now many people sabotage their manners. The development of moral values of children and raising them is very important, by mentioning that children and youth struggled to their country. The purpose of a scientific and in-depth study of this research, including knowing the Islamic moral values emanating in AlIsra and means any way to develop for children and adults. The moral values emerging from the verses in Surat Al-Israa include moral values when treating people with the Creator, ethical values when treating people with parents, ethical values when treating people with society and individual moral values.
\end{abstract}

Keyword: values, ethical, development. 
Nur Laily Fauziyah

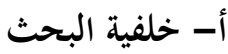

إن هذا القرآن يهدي للتي هي أقوم ويبشر المؤمنين الذين يعملون الصالحات أن لهم أجرا كبيرا، وأن الذين لا يؤمنون بالآخرة لمم عذابا أليما. فالقرآن كتاب الهدى للأمم، لو كنا ندرسه سيساعدنا ونجد القيم التي تستعمل الطرائق في إفاء مشكلات الحياة. لو يخلله ويعمله سيكون فكرية وذوقنا موجها إلى حقيقة الإيمان احتياجا لاستقرار وهدوء الفردية والإجتماعية. والقرآن بأسلوبه تيج العقل وتمس الشعور وتحسنا أي يفوقنا لأن يستلم ويعطي المودة والمحبة حتى يوجهنا لاعطاء بعض ما نملك لأهمية ومصلحة الأمه.

أما نزل القرآن على أمة بأغراض، كما قال قريش شهاب، منها: تنظيف العقل وتزكية النفس ويثبت او يرسخ تيقنا على الله, ويعلم الإنسانية العدالة والأداب, ويخترع الإتحاد والوحدة لجميع العالم, ويحث الناس فكرية وتعاونا في جميع الحياة الإجتماعية, ويييد فقر الجمادية والروحية والجاهلية والآلم والمرض وغير ذلك, ويتخد الصواب والعدالة مع الرحمة والرحيم, ويشدد دور العلوم والتكنولوجية. 1 أما الإسلام يبين بكل حزم وصراحة أن حجة الإيمان هي النفس التزكية، وحجة الإسلام هي الأخلاق الحسنة. إن الأخلاق جماع الدين. والخلق يعتبر أول انعكاس لصحة الدين لأن الإيمان يتجاوز مرحلة بجاهدة النفس وملها على الطيب إلى ضرورة الإيمان وسجية لها. والشاهد على هذا خلق رسول الله لِق

$$
\text { 1 . قريش شهاب "Wawasan Al-Qur'an" (بندونج: ميزان، 2000م) ص: } 12
$$

Al Marhalah : Jurnal Pendidikan Islam. Volume. 2, No. 2 November 2018 


$$
\text { والقيم الأخلاقية في سورة الإسراء }
$$

وحينما نتدبر في حقيقة الإيمان نجده ويستلزم في درجاته المرتقية كل الفضائل الإنسانية، لأن الله

الذي هو الحقيقة الكبرى التي ترتبط بها جميع أركان الإيمان وفروعه، يأمر بكل الفضائل، زمنها الفضائل الخلقية وينهى عن كل الرذائل، ومن ضمنها الرذائل الخلقية، والمؤمن يجد نفسه ملزما باتباع ما أمر الله به، واجتناب ما فهى الله عنه، ولإيمان من التأثير على الإنسان ما ليس لآية قوة أخرى داخلة في النفس أو خارجة عنها.2 فالإيمان الذي هو أثقل الفضائل عند الله تعالى هو مظهر من مظاهر الكمال الخلقي في الإنسان، وإذا تتبعنا الأعمال وجدنا العبادات أيضا من مظاهر الكمال الخلقي في الإنسان. إن حسن الخلق زينة الإنسان وهي التي تجعله محبوبا في المجتمع وهي من أسباب سعادة الإنسان في هذه الحياة ولدخوله في الجنة في الآخرة، وسوء الخلق من أسباب شقاوة الإنسان ودخوله النار في

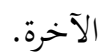

أن القيم الخلقية في الإسلام يصورها القرآن الكريم، وقد تشكلت بصورة حية في أخلاق الرسول

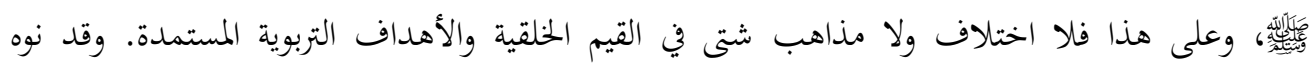
الإسلام بالخلق الحسن ودعا إلى تربيته في المسلمين وتنمية في نفوسهم، واعتبر إسلام العبد بحسن خلقه قال

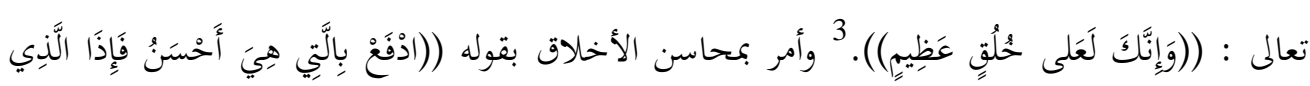
4

2. عبد الرمن حسن حبنكة الميداني "الوجيزة في الأخلاق الإسلامية وأسسها" (بيروت: مؤسسة الريان، 1418 هـ/ 1998م)، ص: 27 3.3. سورة القلم [ 68]: 4

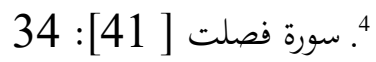




\section{Nur Laily Fauziyah}

كما نظرنا في زمن الآن كثير من الناس تخريب آداجمم، فتنمية القيم الأخلاقية من الأولاد وتربيتها مهمة جدا، بذكر أن الأولاد والشباب مجاهد لبلادهم. واختارت الباحثة موضوع "القيم الأخلاقية في سورة الإسراء" للأسباب الآتية: أن في هذه السورة تشتمل آيات الخلق منظمة ومرتبة. وإن الأخلاق أو الخلق الحسنة من أمور نافعة، والحسن الخلق يصير ويحصل نجاحا للدعوة الإسلامية وأثرا للإصلاح الباطني والظاهري وسيحملها على درجة عالية حتى سعادة في الدنيا والآخرة. بذكر أن وبدورة الزمان كثير التغير في جميع المجلات، لا سيما أزمة أخلاقية، وهي وقعت على الأولاد والشباب. مع أفم جيل مواصلة الأمة والدين. أفم متأثر طاقة العربية التي انتشرت من الاعلام كالتلفيزين والإنترنيت وما إلى ذلك. لذا بتحليل تفسير هذه آيات القرآن حول الأخلاقية تريد الباحثة أن تعطي الصورة الكاملة والإقتراح حول تنمية القيم

$$
\begin{aligned}
& \text { الأخلاقية الإسلامية على الأخص للأولاد والشباب أو الكبار. } \\
& \text { ب- تحديد المسائل ومشكلات البحث }
\end{aligned}
$$

فنظرا قوله تعالى وأحاديث النبوي حول الأخلاقية، فتنمية القيم الأخلاقية خطير. وفي القرآن الذي يتحدث عن الأخلاق كثيرة من السور كما ذكر في سورة يوسف، لقمان، سورة الحجرات، سورة الإسراء وغير ذلك. بذكر أن استطاعة الباحثة المحدودة، ففي هذا البحث نحدد تفسير الآيات 23-41

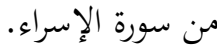
أما المشكلات اللاتي تحتاج إلى دراسة علمية وعميقة والإجابة من هذا البحث "القيم الأخلاقية

$$
\text { 1. 2. مورة الإسراء منها: }
$$




$$
\text { والقيم الأخلاقية في سورة الإسراء }
$$

3. ما هي الوسائل لتنمية القيم الأخلاقية الإسلامية؟ ولإلغين

$$
\text { ج - مناهج البحث }
$$

البحث في هذه الرسالة بحث مكتبي يعنى مصادر البينة التي تحتاج في هذه الرسالة مادة مقروءة أو

عمل الكتابة متصل هذذا البحث. ومناهج التي تستخدم الباحثة في هذا البحث كثيرة كما ذكر مُعَّمَ رواس قلعه جي في كتابه "طرق البحث في الدراسات الإسلامية"، ومن أهمها كما يلي: 1. المنهج الإستقرائي: ويكون بتتبع الموضوع واستقرائه في مظانه، وجمع المعلومات المتعلقة به من هذه المظان. فعملية الباحثة في هذا البحث منها: جمع الآيات التي تتحدث عن القيم الأخلاقية وجمع المعلومات من آراء العلماء وكتابته من الكتب المتعلقة بهذا البحث

2. تم المنهج الإستدلالي: هو المنهج الذي يعنى بالتدليل على كل ما تطرحه الباحثة من الأفكار. فبهذا المنهج يطلب وتستدل الباحثة من أحاديث النبوي التي دالة على أهمية وفضيلة الأخلاق. 3. المنهج الوصفي: هو وصف الواقع لإصدار الأحكام الصحيحة لدراسة الإسلامية. وتستخدم الباحثة هذذا المنهج لكشف ما تضمنت في الآية المذكورة في سورة الإسراء والقيم الأخلاقية فيها. 4. المنهج التحليلي: هو المنهج الذي يعنى بتحليل ما استقرأته الباحثة من النصوص والأفكار. وبذلك:ملاحظة الفروق الواضحة بين آية 23-41 من سورة الإسراء من محتويات فيها. وأخذ الآيات من السور الأخرى التي تتعلق بالآيات المذكورة واستقراها. وبسط التحليلية وشرح وجيز

$$
\text { منطيقية وبرهانية من كل الآية. }
$$

5. المنهج الاستنباطي: هو الذي يركز فيه الباحثة على استنباط الأحكام حول حقيقة القيم الأخلاقية

$$
\text { في آية 23-41- n من سورة الإسراء. }
$$


Nur Laily Fauziyah

\section{د - تعريف القيم الأخلاقية}

تعريف القيم لغة, القيمة جمع القيم هي النوع من قام، قيمة الإنسان قامته. 5 قال ابن منظور في كتابه

أن القيمة واحدة القيم، واصله الواو لأنه يقوم مقام الشيئ. والقيمة ثثن الشيئ بالتقويم. 6 وأن القيمة: قيمة الشيئ قدره. وقيمة المناع: ثُنه. ومن الإنسان: طوله، جمع قيم. ويقال: ما لفلان قيمة: ما له ثبات ودوام

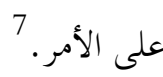
ومن تعريفات أن القيمة هي قيمة المرء ما يحسنه.

أما تعريف القيم إصطلاحا, القيم عند مقداد يلجين هي علم السلوك التفضيلي فالإنسان يبحث دائما عن أفضل. 8 القيمة هي كل ما يعلى من قوة الضمير ويزيد اشتداده مع مراعاة النتائج التي تحفف إليها الأفعال الخلقية التي تعمل على المحافظة على القيم الأخلاقية. 9 إذن القيمة هي كل ما يدل على الخير مع مراعاة النتائج التي تمدف إليها الأفعال الخلقية.

6. '. لويس معلوف الإمام العلامة ابن منظور "السان العنجد في اللغة" (دون ذكر المطبعة سنة الطبع). ص: 663 (القاهرة: دار الحديث، 1423هـ/2003م)، ص:

547

7 7 إبراهيم أنيس واخوانه، مجمع اللغة العببية "المعجم الوسيط" ط4، (القاهرة: مكتبة الشروق الدولية،

1426هـ/2005م)، ص: 768

8. مقداد يلجين "القيم الأخلاقية" (القاهرة: مطابع لدجوي، مكتبة الخانجي، دون سنة الطبع)، ص:

9. فهمي يُمَّم علوان "القيم الضرورية ومقاصد التشريع الإسلامي" (دون ذكر المطبعة، 1989م)، ص:

$-76-$

132

Al Marhalah : Jurnal Pendidikan Islam. Volume. 2, No. 2 November 2018 


$$
\text { والقيم الأخلاقية في سورة الإسراء }
$$

ثم تعريف الأخلاقية هي الخنق او الخلقية يعنى الطبيعة، والخلق هي السّجيّة لأن صاحبه قد قدّر عليه. 10 وخص الملنق بالقوي والسجايا المدركة بالبصيرة قال تعالى في سورة القلم: 4. 11 من هنا استطاعت الباحثة تلخيص من التعريفات السابقة الأخلاق وهي سجايا الإنسان التي توصف بالحسن والقبح. أما الأخلاق اصطلاحا هي: الهيئة التي بما تستعد النفس لأن يصدر منها الإمساك او البذل، فهو صورة النفس الباطنة، وعند القدماء ملكة تصدر بها الأفعال عن النفس من غير تقدم روية، وفكر وتكلف. 12 وأما الإمام مُحمّم الجرجاني رأى أنه الخلق هي عبارة عن هيئة للنفس راسخة تصدر عنها الأفعال بسهولة ويسر من غير حاجة إلى فكر وروية، فإن كانت الهيئة بحيث تصدر عنها الأفعال الجميلة عقلا وشرعا بسهولة سميت الهيئة خلقاً حسناً وإن كان الصادر منها الأفعال القبيحة سميت الهيئة التي هي المصدر خلقا سيئا. ${ }^{13}$ وإن موضوع الأخلاق هو روح أي نظام من أنظمة الحياة. 14

10. أبو الحسين أحمد بن فارس بن زكريا "معجم مقايس اللغة" تحقيق عبد السلام مُعَّمَ هارون ج1، (مصر:

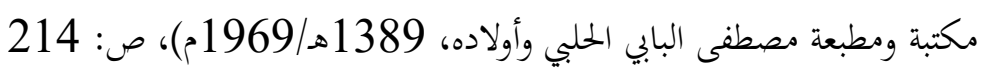

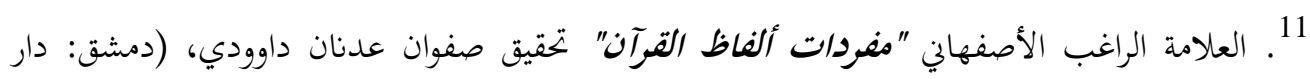

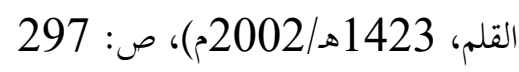
12. مُمَّمَ الباكر البرازي "أخلاقيات مهنة التربية والتعليم في الكتاب والسنة" (عمان: مؤسسة الوراق للنشر والتوزيع، 2001م)، ص: 23

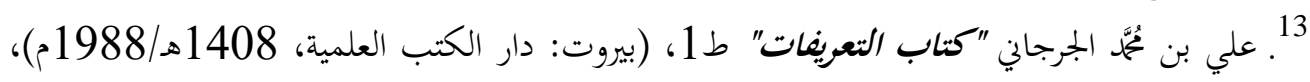
ص: 101 14. عبد الرمن حسن حبنكة الميداني "الأخلاق الاسلامية وأسسها" ج1، (دمشق: دار القلم، 1407هـ/1987م)، ص: 10 


\section{Nur Laily Fauziyah}

والخلق عند الغزالي (ت: 505هـ/1085م) هي "هيئة في النفس راسخة عنها تصدر الأفعال بسهولة ويسر من غير حاجة إلى فكر وروية، فإن كانت الميئة بحيث تصدر عنها الأفعال الجميلة المحمودة عقلا وشرعا، سميت تلك الميئة خلقا حسنا، وإن كان الصادر عنها الأفعال القبيحة سميت الهيئة التي هي المصدر خلقا سيئا ".

فاستخلصت الباحثة تعريف الأخلاق وهي صورة النفس الباطنة فطري أو مكتسب راسخة تصدر عنها الأفعال الحسن والقبح بسهولة ويسر من غير حاجة إلى فكر ورويّة. فقيمة الأخلاق مرتبطة هذه القيمة المادية والقيمة المعنوية لارتباط السلوك الأخلاقي كما معا. إن الأخلاق تكتسب قيمتها في نظر الإسلام من أربعة روافد: الأول, القيمة الإلهية باعتبارها وحيا إلهيا وإرادة إلهية وكل ما يوافق إرادة الله يكون له قيمة وقداسة عند المؤمن, الثاني القيمة الإنسانية: لأن الإنسان له قيمة والأخلاق من الناحية ....الفعل الأخلاقي بل تعتبران روح السلوك الأخلاقي, والثالث القيمة المادية: لأن الأخلاق مهما كانت بعيدة عن المادة من حيث المصدر والغاية فإنها متصلة بالمادة ويترتب عليها جزاء مادي ومعنوي, الرابع القيمة النظرية: فالحق والباطل قيمتان، الأول خير والثاني شر. والأول علم والثاني جهل. إذن قيمة الأخلاق في الإتحاه الإسلامي قيمة عظيمة بتمع بين قيم السماء والأرض ولهذا فقد اهتم الإسلام كل الاهتمام بالأخلاق، ويدعو الناس إليها دائما لأن سعادة المرء مرهونة بها في هذه الحياة وفي الحياة الأخرى أيضا. 15 15 الهيئة هي صورة النفس الباطنة

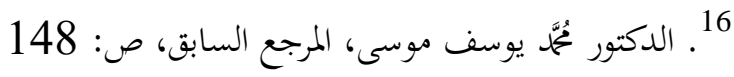
17 مقداد يلجين، "القيم الأخلاقية" المرجع السابق، ص: 309

Al Marhalah : Jurnal Pendidikan Islam. Volume. 2, No. 2 November 2018 


$$
\text { والقيم الأخلاقية في سورة الإسراء }
$$

والمفهوم همذه القيم الأخلاقية تقضي على التفريق والتمييز ما بين الأخلاق النظرية والعملية

التطبيقية التي تطور المنظور إلى عمل جاد، وأخلاق يؤثر ويتأثر ويؤدي تفاعله انعكاسا على الأوضاع

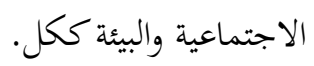

\section{هـ - الأسس والغاية من الأخلاقية الإسلامية}

إن الأساس هو أصل البناء، أما أسس الأخلاق الإسلامية هي أسس فكرية عملية، وفطرية وجدانية، وإيمانية، كما أن أسس القاعدة الإيمانية في الإسلام وهي أسس فكرية علمية، وفطرية وجدانية، وأخلاقية. 18

أما كوها فكرية علمية: فلأن مكارم الأخلاق يؤيدها الفكر العلمي ويستحسنها، ويحث عليها، ويوجب ما يوجب منها. ولأن رذائل الأخلاق يؤيد العقل اجتناها، ويستقبحها، ويحث على البعد عنها،

$$
\text { ويحرم ما يحرم منها. }
$$

وأما كوها فطرية وجدانية: فلأن في فطر الناس الوجدانية ميلا إلى مكارم الأخلاق، ورغبة داخلية بالتزامها وممارسة كل سلوك تدفع إليه، ولأن في فطر الناس الوجدانية نفورا واشمئزازا من رذائل الأخلاق، ورغبة داخلية باجتناهما واجتناب كل سلوك هو من آثارها.

وأما كوغا إيمانية: فلأن القاعدة الإيمانية في الإسلام تلزم بطاعة الله في أوامره ونواهيه، وترغب بالعمل بوصاياه. وقد اشتملت أوامر الله ونواهيه ووصاياه على التوجيه للعمل بكارم الأخلاق واجتناب رذائلها، وقرنت ذلك بالوعظ بالثواب لمن أطاع، والوعيد بالعقاب لمن عصى. 19

18 1. عبد الرمن حسن حبنكة الميداني "الأخلاق الإسلامية وأسسها" ج1، (دمشق: دار القلم، 1407هـ/1987)، صند: 25 


\section{Nur Laily Fauziyah}

و أما الغاية من الأخلاقية الإسلامية يعني, أصل الغاية هي الراية، أي القصبة التي يصاد بها العصافير.20 والمراد بغاية القيم الأخلاقية هنا ما الذي تحصل من عملية الأخلاق. أن الغاية من التزام فضائل الأخلاق والابتعاد عن رذائلها تنقسم إلى عنصرين: الأول: الظفر بالسعادة مؤجلة دنيا، وسعادة مؤجلة أبدية خالدة، وهاتان السعادتان تأتيان جزءا على أعمال صالحة ابتغى بها وجه الله تبارك وتعالى، وذلك لا يكون إلا مع الإيمان بالله. الثاني: تحقيق أقساط من السعادة المستطاعة التحقيق في ظروف الحياة الدنيا، وهي أنواع السعادة التي تمنحها سنن الله في

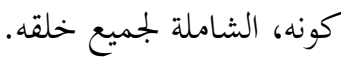

$$
\text { و - القيم الأخلاقية في سورة الإسراء }
$$

اكتشفت الباحثة الآية 23-41 من سورة الإسراء فوجدت القيم الأخلاقية الإسلامية ، منها: 1. - القيمة الأخلاقية عند معاملة الناس بخالقه

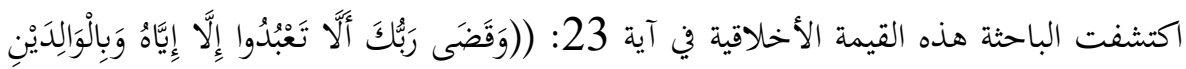

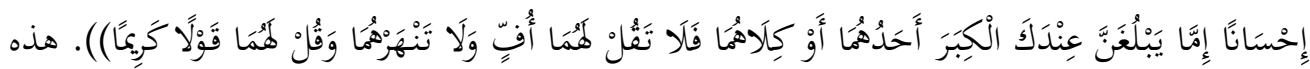
الآية دالة على في الشرك بالله إما في ألوهيته وعبادته. هذه القيمة الأخلاقية من سورة الإسراء بآية سابقة هي ترك الشرك بالله شيئا. ويعبد إلا الله ليس للآخر. وفضيلة هذا الأخلاق كما ورد الحديث: عن أبي

19 19

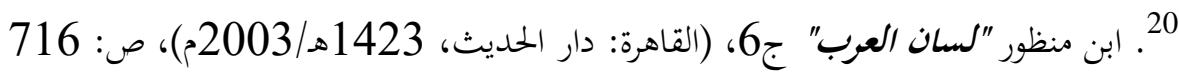
$-80-$

Al Marhalah : Jurnal Pendidikan Islam. Volume. 2, No. 2 November 2018 


$$
\text { والقيم الأخلاقية في سورة الإسراء }
$$

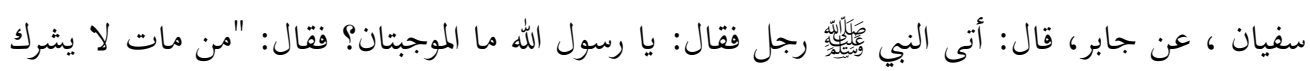

$$
\text { 2. بالله شيئا دخل الجنة. ومن مات يشرك بالله شيئا دخل النار". } 21
$$

ومن القيمة الأخلاقية التي تضمنتها الآية 23 هو أخلاق الولد مع الوالدين، أمر الله أن يعامل

الولد بإحسان إليهما احسانا تاما في المعاملة. فالله تعالى جعل أهمية الإحسان إلى الوالدين بعد توحيده

$$
\text { وعبادته، ولم يقدم على الوالدين مخلوقا. }
$$

وكيفية الإحسان إليهما كما ذكر في الآية المذكورة، منها:

أ)- إن إحسان الوالدين لا يختص بأن يكون مسلمين، بل إن كان كافرين ببرها ويحسن إليهما.

ب)- ومن الإحسان إليهما والبر بكما إذا لم يتعين الجهاد ألا يجاهد إلا بإذغما ولا تنهرهما أي ولا يصد منك إليهما فعل قبيح.

ج)- فلا تقل لمما أف في أي حال، ولا سيما حال الضعف والكبر والعجز عن الكسب، لأن التأفف هو أدنى مراتب القول السيئ. د)- الاحترام والاكرام إليهما بالقول أو الكلام الكريم أي قولا لينا طيبا حسنا لطيفا. هو أن يقول له: يا أبتاه يا أماه أي لا يدعوهما بأسمائهما، ولا يرفع الصوت أمامهما، ولا يحملق بنظره فيهما. هـ)- التواضع لمما بإظهار الرحمة والشفقة عليهما.

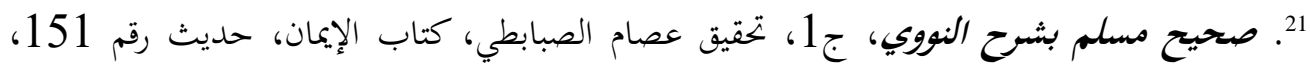

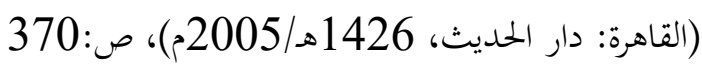




\section{Nur Laily Fauziyah}

و)- الدعاء عليهما أي أن يدعو الولد لمما الرممة من الله في حال كبرها وعند وهاتما. ولفظ الدعاء "رب ارمهما كما ربياني صغيرا". إذا كان الوالدان كافرين فللولد أن يدعوا لمما حال الحياة

$$
\text { بالهداية والارشاد، وأن يطلب لمما الرمة بعد حصول الإيمان. }
$$

أما كيفية الاحسان والبر إلى الوالدين بعد وفاتما، منها: الصلاة عليهما والاستغفار لمما, انقاذ

$$
\text { عهدهما, إكرام صديقهما, صلة الرحم التي لا رحم لك إلا من قبلهما. }
$$

ومن فضيلة بر الوالدين يعني: بر الوالدين والإحسان إليهما أحب إلى الله, بر الوالدين مقدم أفضل من الجهاد في سبيل الله, بر الوالدين المرافق لدخل الجنة لأن رضى الله في رضى الوالدين وسخط الله في سخط الوالدين.

3. القيمة الأخلاقية عند معاملة الناس مع المجتمع

المراد بالمجتمع هي تتكون على الأقارب والمساكين وابن السبيل واليتامى والآخرين.

$$
\text { (أ. أخلاق الناس على الأقارب والمساكين وابن السبيل }
$$

قد وجد هذه القيمة الأخلاقية في سورة الإسراء، أحدها أخلاق الناس على ذي القربى والمساكين وابن السبيل بإيتاء حقوقهم. ومن حقوقهم هي التسامح، التعاون والتكافل بصلة الرحم. التعاون والتكافل سمة المجتمع المسلم. يجعل القرآن الكريم لذي القربى والمسكين وابن السبيل حقا في الأعناق يؤدي بالإنفاق، فليس هو تفضلا من أحد على أحد إنما هو الحق الذي فرضه الله، ووصله بعبادته وتوحيده الحق الذي يؤديه المكلف، فيبرء ذمته، ويصل المودة بينه وبين من يعطيه.

أن الأغلب في الأقارب التنافس والحسد والعداوة، فكأنه باقيهم إن كافأقم بأفعالمم تركتهم جميعا وعطلت هذه الفضيلة العظيمة التي هي صلة الرحم لأن أقاربك لا 


$$
\text { والقيم الأخلاقية في سورة الإسراء }
$$

يخلون غالبا من أن يقابلوك بالأفعال الذميمة وتعطيل صلة الأرحام لا ينبغي أن يقع من كامل فأحوج الاضطرار إلى صلة الأرحام أن لا تكافئوا بما يصدر منهم، وإن يعرض الإنسان عن مقابلتهم بسوء أفعالمم بل يحتسب أجره على الله تعالى ويبالغ في الإحسان إليهم ليكتب له أجران عظيمان أجر كسر نفسه

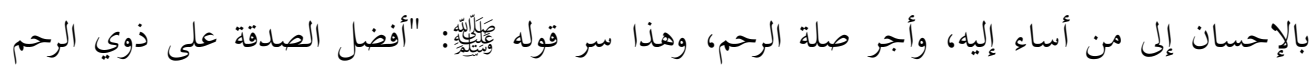

$$
\text { الكاشح". } 22 \text { (ب. أخلاق الناس على اليتيم }
$$

ومن القيمة الأخلاقية في سورة الإسراء بآية مذكورة النهي عن تقريب أموال اليتامى. إن كفالة

اليتيم فرض كفاية يجب على الأمة كلها، فإذا قام به البعض سقط عن الباقين. 23 والإسلام اهتم بشأن اليتيم الاهتمام البالغ من ناحيات. ورعاية أمور اليتيم تشمل كل احتياجاته التي يحتاجها أمثاله، ومن ذلك: حسن تربيته وتعليمه التعليم المناسب لأمثاله، ويهذهم بأخلاق حسن وموقف الرفق اليتيم وعدم التغليظ عليهم حتى حزنا لهم.

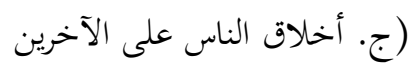

ومن أخلاق الناس على الآخرين كما ذكر في سورة الإسراء منها النهي عن قتل الأولاد ونفس الآخرين اللاتي حرم الله عليه إلا بالحق. إذا كان الآباء أن يقتل ولده فأعظم ذنبه. ويقتله لأجل الفقر أي خشية الإملاق فهو من سوء الظن إلى الله. وعلى الآباء أو الوالدين أن يعرف أن الله أغنى منه وسيعطيهم الرزق، بل أكلا إليه. القتل العدوان إثم كبير، وجرم عظيم. توعد الله عليه العذاب الشديد.

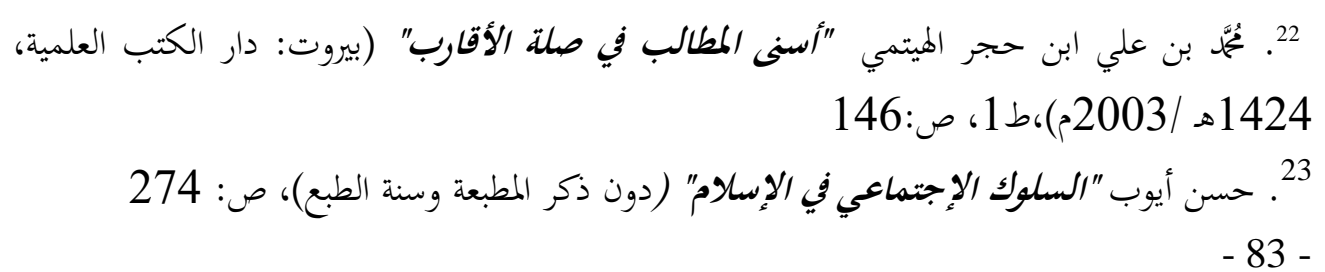
Al Marhalah : Jurnal Pendidikan Islam. Volume. 2, No. 2 November 2018 
Nur Laily Fauziyah

4. - n القيمة الأخلاقية الفردية

$$
\text { هذه القيمة التي ذكرها في سورة الإسراء منها: }
$$

أمر الله عز وجل بالوفاء بالكيل وبالوفاء بالعهد أمرا صريحا في عدد من آيات القرآن الكريم، كما فهى بشدة عن نقض العهد واليمين. أما في الوزن فقد ركز على دقته، وجعله بالقسطاس، ليس القسطاس فحسب بل المستقيم. لو نظرنا إلى عملية الكيل لوجدها واضحة مكشوفة، فلما يستطيع الإنسان الغش فيها، وكثيرا ما ينكشف أمره ويعلم تلاعبه، لأن الكيل أمام الأعين والتلاعب فيه مكشوف. والوزن مجال واسع للتلاعب، ولدى التاجر ألف طريقة وطريقة يبخسون بها الوزن دون أن يدري بمم أحد لأن الميزان كما نعلم رافعة من النوع الأول، عبارة عن محور ارتكاز في الوسط. وكفة القوة في ناحية، وكفة المقاومة في الناحية الأخرى. فأي نقص في الذراعين يفسد الميزان. 24

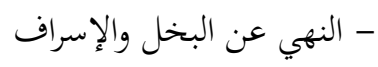
أنه تعالى لما أمره بالإنفاق في الآية المتقدمة وشرح وصف عبادة المؤمنين في الإنفاق, أي لا تمسك عن الإنفاق بحيث تضيق على نفسه وأهل في وجوه صلة الرحم وسبيل الخيرات. ولا تتوسع في الإنفاق توسعا مفرطا بحيث لا يبقى في يد شيء. أن لكل خلق طريف إفراط وتفريط وهما مذمومان. فالبخل إفراط في الإمساك، والتبذير إفراط في الإنفاق وهما مذمومان، والخلق الفاضل هو العدل والوسط. 25

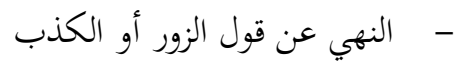

$$
\begin{aligned}
& \text { 24. تفسير الشعراوي، ج14، ص: } 8529 \\
& \text { 5. تفسير الرازي، ص: } 159
\end{aligned}
$$

Al Marhalah : Jurnal Pendidikan Islam. Volume. 2, No. 2 November 2018 


$$
\text { والقيم الأخلاقية في سورة الإسراء }
$$

إن قول الزور يشمل شهادة الباطل، والحكم الجائر، ورمي الأبرياء بما هم منه براء، والقول على الله بغير علم، فكل ذلك داخل في قول الزور، هذا وإن شاهد الزور يسيء إلى نفسه، إذ يبيع آخرته بدنيا غيره، ويسيء إلى من شهد له بإعانته على ظلمه، وإلى من شهد عليه بإضاعة حقه، وإلى القاضي بإضلاله عن المجة، وإلى الأمة بزلزلة الحقوق فيها، وعدم الاطمئنان عليها. ز - تنمية القيم الأخلاقية عند الأطفال والبالغين 1 بحقيقة أن تنمية رغبة الدينية، تكوين الشخصية او الطبيعة وتنمية القيم الأخلاقية الإسلامية تبدأه منذ الجنين في الرحم، لأن عاطفة او موقف الأم ستأثر نشأة الجنين في رحمها. ثم طريقة تنمية القيم الأخلاقية الإسلامية للطفل بهذا العمر كما يلي:

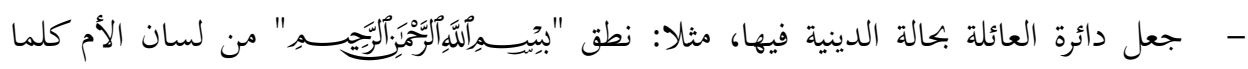
ترضعه، تنوب لباسه / ثوبه، بغسل البدن كله وغير ذلك، ونطق "الحمد لله" بعد نصر طفلها.

$$
\text { ويزاد بأغنية ودندنة رحيم الذي تضمنت فيها. }
$$

- - جعل معاشرة الأب والأم احسانا تاما ومتناسق مودقما، وكذلك رمهما ودقتهما في ضم الطفل سيظهره ويسمعه الطفل، وذلك ستأثر على نشأته وتكوين اخلاق الطفل.

$$
\text { تنمية القيم الأخلاقية في فطرة الطفولة الأولى (2-5 سنوات) }
$$

عرفنا أن الأولاد في هذا العمر مائل التحرك، اللعب، يحب القدوة والتجريبات على كل شيئ في بيئته. وذلك لأن فجميع الكل جديد عند الأولاد. يريد أنْ يعرفه بخبرة نفسه. يمر باللعب سيحصل على الخبرة، المهارة والتيقن في نفسه ويشعرهم بالأمن على بيئنه. 


\section{Nur Laily Fauziyah}

الطريقة التي تقدم لتنمية القيم الأخلاقية عامة، على الأخص في سورة الإسراء المذكورة في هذا العمر يمر ببيئه الأسرة وجمعية اللعبة الإسلامية، منها بمناهج وطروق. أما منهج الإسلام وطريقته في اصلاح الصغار او الأولاد، فيعتمد على شيئين أساسيين:التلقين والتعويد. ونقصد بالتلقين الجانب النظري في الاصلاح والتربية. ونقصد بالتعويد الجانب العملي في التكوين والإعداد. - - القيمة الأخلاقية عند معاملة الناس بخالقه

طريقة تنمية هذه القيمة في دائرة الأسرة وفرقة اللعبة مثلا: الأب والأم او المربون بأن يلقن أولادهم كلمة "لا إله إلا الله". لما ورد الحاكم عن ابن عباس رضي الله عنهما عن النبي "افتحو على صبيانكم أول كلمة بـ "لا إله إلا الله". وهذا هو الجانب النظري. أما الجانب العملي هذا التلقين فهو تهيئة الولد وتعويده أن يؤمن بقرارة نفسه وأعماق وجدانه ان لا خالق ولا مبدع ولا إله إلا الله سبحانه. ولا يكون ذلك إلا عن طريق الآثار التي يراها الطفل كالزهرة، والسماء، والأرض، والبحر والإنسان وغيلرها من المخلوقات ليستتج ذهنيا، ويستدل عقليا على المؤثر وهو الله سبحانه. - - - القيمة الأخلاقية عند معاملة الناس بالوالدين بر الوالدين واحساغما أحد من القيمة الأسرة. وطريقة تنمية هذه القيمة على الوالدين للطفل يبدأ بنفسه. مثلا، احترام الأب على الأم دائما ويرحمها او يرحم اعضاء الأسرة. بالعكس طاعة الأم على الأب واحترامه. فبذلك سيلاحظ الطفل والديه ويتبعهما، ويعود طاعتهما، ويحترهما ويرحمهما بنطق لطيف عليهما واقارهما والاجتماعية.

$$
\text { 26 تُحَّد عبد الله علوان "تربية الأولاد في الإسلام" ج2، المرجع السابق، ص: } 679
$$




$$
\text { والقيم الأخلاقية في سورة الإسراء }
$$

3. ت تنمية القيم الأخلاقية في فطرة الطفولة الثانية من عمر 6-12 سنوات

نمو النفس الإجتماعية في هذا العمر مهم. إذا كانت الأولاد بعمر ثلاثة عام يحتاج رفيق اللعب،

فالأولاد في هذا العمر يجتاج رفيقا لينمو حول تخيلاته بتحكي او بتقص ويقلد الراشد الذي يهتمهم. أما طريقة تنمية هذه القيمة الأخلاقية للأولاد في هذا العمر يعني بالنصيحة والقدوة والقصة والتاريخ او الحكاية وغير ذلك. - - - القيمة الأخلاقية عند معاملة الناس بخالقه طريقة تنمية هذه القيمة للأولاد في هذا العمر أحدها بالنصيحة. يمر بهذه الطريقة ينهى الوالد أولاده لشرك الله ويأمرهم بالصلاة بتدليل آيات القرآن، أحدها من سورة لقمان آية: 13(وإذ قال لقمان لابنه وهو يعظه يابنيّ لا تشرك بالله إنّ الشّرك لظلم عظيم)). وطريقة أخرى بالقدوة والتعويد، ههنا يدعو الوالد أولاده لصلاة الجماعة في البيت او المسجد، وكذلك يعود المربون تلاميذهم لصلاة الجماعة في المصلى حول المدرسة. وهذا هو الجانب العملي في تعويد لأن يعبد الله. - - - القيمة الأخلاقية عند معاملة الناس بالوالدين طريقة تنمية هذه القيمة يعني للأولاد ببر والديهم أحدها بالنصيحة. والآخر يهكى المربون تلاميذهم، كما حكاية الرجل الطاعة على والديه او حكاية الرجل العقوق على والديه. مثلا، ـ - مكاية صحابة "ألقمة" العاقة على والديه. 


\section{Nur Laily Fauziyah}

أحد من هذه القيمة الأخلاقية المذكورة في سورة الإسراء أخلاق المرء او الأولاد على أقاربمم والمساكين واليتمى وابن السبيل. أما طريقة تنمية هذه القيمة على الأولاد في هذا العمر بالقدوة والتعويد، مثلا، الوالد بأن يدعو أولاده صلة الرحم إلى مسكنة أقاركم كي يعرفهم، ويظهر رمة

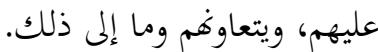
والمربون بأن يلقنوا أولادهم رحم اليتمى والمساكين والفقراء وابن السبيل، وكذا بأن يدعوهم إلى مؤسسة التربية لليتمى، ويجمعهم الفلوس او الهدية باللفافة ويعطي عليهم. - - - - القيمة الأخلاقية مع الأقارب والمساكين واليتامى يبدأ بهذا العمر يعرف الوالدان أولادهما على أقاربه والضعفاء ويحسنهم بأن يدعوه وأعضاء أسرته لصلة الرحم إلى مسكنة شيوخه وأقاربه بحمل هدية باللفافة. ويلقن الأب أولاده لأن يرحم المساكين واليتمى وينطق عليهم بكلام لطيف وطيب. حينما جاء الفقير او المسكين امام بيته لطلب الأشياء او المال، يعطي الأب إليه بظهار ولده، احيانا يأمر الأب ولده لأن يعطي

$$
\begin{aligned}
& \text { الصداقة او المال عليهم (الضعفاء والمساكين). } \\
& \text { - - م- القيمة الأخلاقية الفردية }
\end{aligned}
$$

القيمة الأخلاقية الفردية كما ذكر في سورة الإسراء أحدها النهي عن الإسراف. أما طريقة تنمية هذا الأخلاق على الأولاد مثلا بأن لا يعطي الوالدان كثرة الفلوس على أولاده. لو كانت أقاربه يعطيه الفلوس، فيطلب الوالد فلوسه لتوفير. لأن ذلك يعوده اقتصادا. أما تنمية القيمة الأخلاقية للبالغين هي بمنهج الإسلام وطريقة في إصلاح الكبار وهم سن ما بعد البلوغ يعتمد على ثلاثة أمور أساسية:الربط بالعقيدة, تعرية الشر , تغيير البيئة 


$$
\text { والقيم الأخلاقية في سورة الإسراء }
$$

أما الربط بالعقيدة يتولد عند الكبير الشعور بالمراقبة، والخشية من الله في السر والعلن،

وهذا ما يقوي في نفسه الإرادة الذاتية ليكف عن المخرمات، ويتحلى بأكرم الأخلاق وأنبل

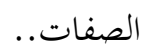

وبتعرية المنكر والشر يقتنع الكبير بترك المفاسد، ويعزم كل العزم على التخلي عن الرذائل، بل يكون عنده الطمأنينة النفسية والقلبية لهجر كل ما هو آثم وفاجر. ثم بتغيير البيئة الإجتماعية يتهيأ لإصلاح الكبير الوسط الخير، والجو الصالح، وحياة الشرف والكرامة ، بل تنصلح مع الأيام أحواله، وتزدان مع الزمن أفعاله وأخلاقه. 27 فما على المربين الاجتماعيين إلا أن يأخذوا بمنهج الاسلام في إصلاح الكبار إن أرادوا

$$
\text { لأفراد الأمة أمنا وخيرا، ولابناء المجتمع سلامة واستقرارا. }
$$

طريقة تنمية هذه القيم الأخلاقية الإسلامية للكبار بالموعظة والوصية والنصيحة بالقصة من آيات القرآن. أو التوجيه القرآن المصحوب بأدوات الاستفهام الانكاري أو بالأدلة العقلية والتوجيه بقواعد التشريع. والآخر الهيمنة بالتأثير الوعظي على الحاضرين حينما في بجلس التعليم، والموعظة بالفعل التطبيق لاجتناب ما أنكر الله ومسابقة الخيرات. أما لأن ينشأ موقف الرحمن والرحيم وكذا شعور حب العطاء على الأقارب والمساكين واليتيم والضعفاء بدعوة جماعة بجلس التعليم لصلة الرحم ويعطي هدية إليهم (الفقراء والضعفاء). وكذا زيارة إلى مؤسسة التربية لليتيم.

$$
\text { -27. عبد الله علوان "توبية الأولاد" المرجع السابق، ص: } 678
$$




\section{Nur Laily Fauziyah}

ثم لتغير بيئة الإجتماعية الإسلامية يحتاج إلى العلوم والخبرة، وهذا بزيارة إلى معهد الدينية وكذا إلى دائرة أخرى التي فيه متقدمة نشيطة دينيتها. أو يمر بالتلفيزيين والاعلام الأخري.

\section{ح}

$$
\text { لقد توصلت من خلال هذا البحث إلى اختلاص النتائج الآتية: }
$$

القيم الأخلاقية المنبثقة من الآيات 23-41 سورة الإسراء: القيم الأخلاقية عند معاملة الناس بخالقه، بأمر الله أن تعبده، والقيم الأخلاقية عند معاملة الناس بالوالدين يعني بإحسان إليهما ، القيم الأخلاقية عند معاملة الناس مع المجتمع بأداء حقوق ذي القربى والمساكين وابن السبيل واليتامى والآخرين، القيم الأخلاقية الفردية بأن ينهي المبذرين. ثم القيمة الأخلاقية عند معاملة الناس مع المجتمع بأداء حق المساكين والضعفاء، أمر الله أن يقول لمم قولا لينا وميسورا بغرض نيل الرحمة من الله سببا ليس له رزقا واسعا لأن يعطيه. ثم القيمة الأخلاقية الفردية بالنهي عن الإسراف والبخل واستمراره، والآية استمرارها النهي عن تقريب مال اليتيم وأمر وف العهد وتمام الكيل والنهي عن قول الزور ثم الأخيرة النهي عن التكبر ثم القيم الأخلاقية عند معاملة الناس بخالقه بتوحيده.

والوسائل لتنمية القيم الأخلاقية الإسلامية منها: (1. عصر الرضاع أو الطفل تنمية قيم أخلاقيتها بالأسوة والقدوة من الوالدين وأعضاء الأسرة (2. فطرة الطفولة الأولى تنمية قيم أخلاقيتها بالتلقين والتعويد (3. فطرة الطفولة الثانية تنمية قيم أخلاقيتها بالنصيحة والقدوة وبالقصة أو التاريخ والحكاية. (4. في المراهقين والمراهقات بعمر الإعدادي والثانوي طريقة تنمية قيم أخلاقيتها بالنصيحة مباشرة والموعظة والتوضيح حول الخيرات والسيئات و المنافع وكذا حول السيئات والمهلكات والمضطرات. ثم للبالغين طريقة تنمية قيم أخلاقيتها بالموعظة والتوجيه القرآني ويمر بالذكر أيام الكبرى لدين الإسلام أو 


$$
\text { والقيم الأخلاقية في سورة الإسراء }
$$

في مجلس التعليم أسبوعية. أوبالوصية والنصيحة مع القصة والخبرة والعبرة من الاعلام. وأصلها منهج لنهاج الإسلام وطريقة في إصلاح البالغين والكبار وهم سن ما بعد البلوغ يعتمد على ثلاثة أمور أساسية،

$$
\text { الربط بالعقيدة، تعرية الشر، وتغيير البيئة. }
$$

\section{DAFTAR PUSTAKA}

أبو الحسين أحمد بن فارس بن زكريا "معجم مقايس اللغة" تحقيق عبد السلام عُمَّمَ هارون ج1،

$$
\text { مصر: مكتبة ومطبعة مصطفى البابي الحبي وأولاده، 1389هـ/1969م }
$$

إبراهيم أنيس واخوانه، مجمع اللغة العربية "المعجم الوسيط" ط4، (القاهرة: مكتبة الشروق

$$
\text { الدولية، 1426هـ/2005م)، (- (2005) }
$$

$$
\text { ابن منظور "لسان العبب" ج6، (القاهرة: دار الحديث، 1423هـ/2003م) }
$$

الإمام العلامة ابن منظور "لسان العرب" ج7، القاهرة: دار الحديث، 1423هـ/2003م

العلامة الراغب الأصفهاني "مغردات ألفاظ القرآن" تحقيق صفوان عدنان داوودي، (دمشق:

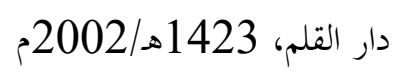

حسن أيوب "السلوك الإجتماعي في الإسلام" , دون ذكر المطبعة وسنة الطبع

عبد الرحمن حسن حبنكة الميداني "الأخلاق الاسلامية وأسسها" ج1، دمشق: دار القلم، 1407هـ 1987م 
Nur Laily Fauziyah

عبد الرمن حسن حبنكة الميداني "الوجيزة في الأخلاق الإسلامية وأسسها" , بيروت: مؤسسة

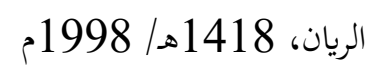

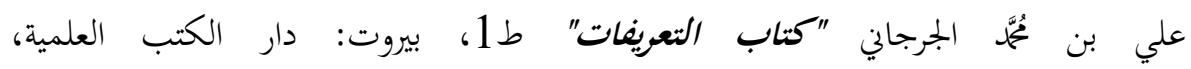

$$
\text { 1988/1408 1988 }
$$

فهمي يُحَّ علوان "القيم الضرورية ومقاصد التشريع الإسلامي" (دون ذكر المطبعة، 1989م)،

مُحُمّم الباكر البرازي "أخلاقيات مهنة التربية والثعليم في الكتاب والسنة" عمان: مؤسسة الوراق

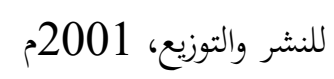

مُعَّمَ بن علي ابن حجر الهيتمي "أسنى المطالب في صلة الأقارب" بيروت: دار الكتب العلمية،

$$
\text { 2003/ 1424 }
$$

$$
\text { مُحَّْ عبد الله علوان "توبية الأولاد في الإسلام" ج2، دون المطبعة }
$$

مقداد يلجين "القيم الأخلاقية" , القاهرة: مطابع لدجوي، مكتبة الخانجي، دون سنة

$$
\text { لويس معلوف اليسوعي "المنجل في اللغة" , دون ذكر المطبعة سنة الطبع }
$$

صحيح مسلم بشرح النووي، ج1، تحقيق عصام الصبابطي، كتاب الإيمان، حديث رقم

$$
\text { 151، القاهرة: دار الحديث، 1426هـ/2005م }
$$

Al Marhalah : Jurnal Pendidikan Islam. Volume. 2, No. 2 November 2018 